\section{Modulação androgênica e estrogênica na próstata: uma abordagem em modelos experimentais de roedores com enfoque na biologia estrutural}

\author{
Androgenic and estrogenic modulation in the prostate: an approach \\ in rodent experimental models with emphasis on structural biology
}

Sebastião Roberto Taboga', Patricia Simone Leite Vilamaior', Rejane Maira Góes
1 Departamento de Biologia, Instituto de Biociências, Letras e Ciências Exatas, Universidade Estadual Paulista (IBILCE/Unesp), São José do Rio Preto, SP, Brasil

Correspondência para:

Sebastião Roberto Taboga Departamento de Biologia, IBILCE/Unesp

Rua Cristóvão Colombo, 2.265 Jardim Nazareth

15054-000 - São José do Rio

Preto, SP, Brasil

taboga@ibilce.unesp.br

Recebido em 1/Nov/2009

Aceito em 6/Nov/2009

\begin{abstract}
RESUMO
O sistema endócrino é uma complexa rede de glândulas e hormônios que regulam muitas das funções do corpo, incluindo crescimento, desenvolvimento e maturação, como as vias de ação de muitos órgãos. A próstata é um importante alvo dos hormônios e sua maturidade funcional e seu desenvolvimento são influenciados pelos níveis de esteroides. 0 presente grupo de pesquisa tem estudado os potenciais efeitos dos agentes esteroides sobre a próstata masculina e feminina do gerbilo da Mongólia (Meriones unguiculatus), utilizando métodos morfológicos e imuno-histoquímicos. Os resultados têm revelado a próstata do gerbilo da Mongólia como uma importante ferramenta para estudos da ação dos hormônios esteroides e seus antagonistas. Arq Bras Endocrinol Metab. 2009;53(8):946-55
\end{abstract}

Descritores

Próstata; desreguladores endócrinos; andrógenos; estrógenos; estroma prostático

\section{ABSTRACT}

The endocrine system is a complex network of glands and hormones that regulates many of the body's functions; including growth, development and maturation, as well as the way several organs operate. The prostate is an important target of hormones and its functional maturity and development are influenced by steroids levels. Our research group has been evaluating the potential effects of the steroidal agents on the Mongolian gerbil (Meriones unguiculatus) male and female prostate using different morphological and immunohistochemical methods. Our results have revealed the Mongolian gerbil prostate as an important tool for the morphofunctional studies of steroid hormones and its antagonist actions. Arq Bras Endocrinol Metab. 2009;53(8):946-55

Keywords

Prostate; endocrine disruptors; androgens; estrogens; prostatic stroma

\section{INTRODUÇÃO}

Reprodução é um fenômeno essencial à vida, fato Aque explica o grande interesse sobre o tema nas mais diferentes áreas do conhecimento científico. Assim, as questões fundamentais que marcam o início das Ciências Naturais procuravam esclarecer os mecanismos envolvidos com a Reprodução e as bases de sua diversidade. A curiosidade a respeito da Reprodução Humana ou
Animal vem assumindo contornos diferentes ao longo dos séculos, à medida que novos conceitos e métodos de análise são desenvolvidos. Entretanto, o volume de investigações sobre os seus mais diferentes aspectos tem sido sempre expressivo, o que torna essa área de pesquisa de grande impacto e competitividade. O termo Biologia da Reprodução é aplicado ao conjunto de conhecimentos interdisciplinares a respeito dos princípios básicos e 
aplicados da reprodução de determinado grupo. Eles resultam de variadas frentes de investigação referentes à organização dos órgãos do sistema genital - nos níveis anatômico, celular e molecular; à regulação hormonal; aos mecanismos de reprodução; ao comportamento reprodutivo; aos métodos de biotecnologia de controle reprodutivo; ao controle de doenças, entre outras.

Muitos grupos de pesquisa do Brasil têm se tornado reconhecidos pela comunidade científica internacional em razão de suas contribuições em algumas dessas frentes, como a Espermatogênese, a Biologia Prostática, a Implantação Embrionária, a Ação de Agentes Toxicológicos e a Reprodução Assistida.

A presente revisão consiste de uma análise crítica de contribuição científica ligada ao grupo de pesquisa em Biologia da Reprodução vinculado ao Conselho Nacional de Desenvolvimento Científico e Tecnológico (CNPq), que vem desenvolvendo desde 1991 pesquisas na área de reprodução. As investigações focalizam, entre outras, a Biologia Prostática de roedores, em especial o gerbilo da Mongólia.

\section{O PRINCIPAL MODELO EXPERIMENTAL}

O gerbilo da Mongólia (Meriones unguiculatus), também conhecido como esquilo da Mongólia ou gerbilo de laboratório, é um pequeno roedor da família $\mathrm{Mu}-$ ridae, subfamília Gerbillinae. Originário das regiões áridas da China e da Mongólia, foi introduzido nas Américas por Victor Schwentker como nova proposta de animal experimental (1). No início, a reprodução em laboratório era ocasional, mas posteriormente foram estabelecidas linhagens com fins específicos para pesquisa. Durante muito tempo as investigações com esse roedor ficaram restritas aos Estados Unidos, contudo nas últimas décadas seu uso tem sido bastante ampliado.

As vantagens do gerbilo da Mongólia em estudos experimentais residem no fato de eles serem consideravelmente menores que os ratos, mas maiores que os camundongos e hamsters. Vantagens relacionadas à manutenção no biotério também ocorrem, visto que eles exibem comportamento dócil em cativeiro e apresentam micção infrequente por serem de origem desértica.

Esse roedor tem sido amplamente utilizado nas mais diversas áreas da pesquisa biomédica como a imunologia (2) e a fisiologia (3). Importantes subsídios para o conhecimento da Biologia da Reprodução dessa espécie têm sido fornecidos por grupos de pesquisa do Japão e do Brasil. A espermatogênese inicia-se na segunda sema- na de idade e os animais adquirem a maturidade sexual a partir da décima semana (4). Segatelli e cols. descreveram as características estruturais do testículo adulto e a duração da espermatogênese (5). Além disso, trabalho relacionado com comportamento do nucléolo das células germinativas ao longo da espermatogênese revelou uma íntima relação entre essa estrutura e os corpos cromatoides (massas de ribonucleoproteínas citoplasmáticas) nessa espécie (6). As relações anatômicas das glândulas acessórias do aparelho genital masculino com a uretra também foram descritas por Pinheiro e cols. (7).

Apesar dos estudos acima mencionados, existiam poucas informações a respeito do complexo prostático desse animal e como é a modulação hormonal para seu funcionamento, o que motivou sua escolha como modelo de estudo. Além disso, as análises iniciais indicavam que os lobos prostáticos do gerbilo apresentavam maior proximidade, sugerindo maior grau de semelhança com a próstata humana (8). Em adição, a análise dos tecidos associados à uretra de fềmeas revelou a existência de glândulas parauretrais (à semelhança das glândulas de Skene em humanos), que após estudos estruturais, bioquímicos e ultraestruturais nos levaram a concluir que se tratava de um complexo prostático feminino, mais volumoso em comparação com outros roedores de laboratório (9). Desde então, os esforços têm sido direcionados aos estudos dessa glândula em machos e fềmeas, com principal enfoque ao controle da modulação hormonal dessa glândula, aliado às alterações estruturais e ultraestruturais.

\section{O CONTROLE HORMONAL NA PRÓSTATA}

A próstata é uma glândula acessória do sistema genital masculino responsável pela secreção e armazenamento de uma ampla gama de produtos do líquido seminal $(10,11)$. Sua secreção fornece aos espermatozoides condições ideais de sobrevivência e viabilidade durante e após a ejaculação. Histologicamente é composta por unidades secretoras túbulo-acinares, envoltas por um estroma rico em células musculares lisas (10).

O controle da diferenciação e da atividade prostática é bastante complexo e, conforme salientado por Lee e colegas (12), depende de uma soma de fatores extrínsecos (hormonais, imunológicos, alimentares e genéticos) e intrínsecos (Figura 1).

Os andrógenos têm sido apontados como o fator extrínseco de maior importância, atuando na homeostase do órgão maduro e também nos eventos que levam ao seu desenvolvimento embrionário e à maturação 


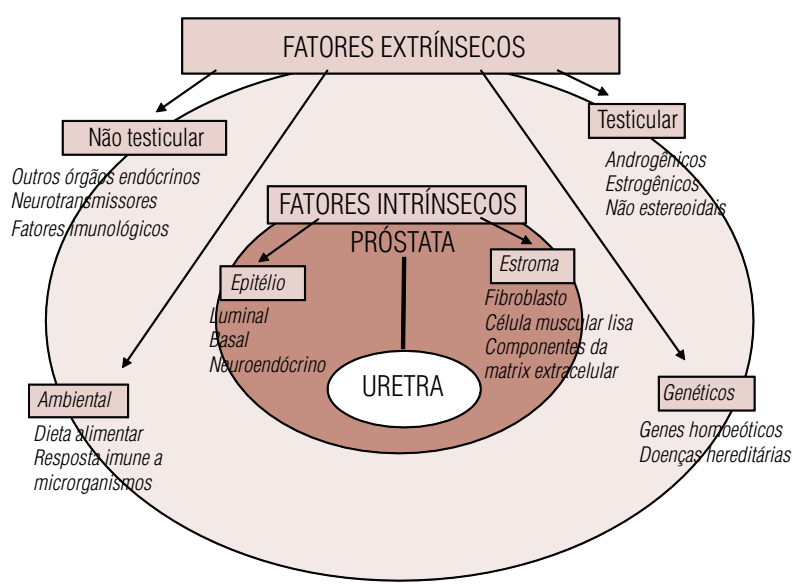

Figura 1. Fatores que influenciam a função prostática. Modificado de Lee e cols. (12).

funcional $(13,14)$. A forma hidroxilada da testosterona, a di-hidrotestosterona (DHT), é a de maior ação na próstata, devido à alta afinidade com os receptores de andrógeno (AR). Vários outros hormônios, como os estrógenos, os glicocorticoides, a prolactina e a insulina, também têm sido implicados no controle da histofisiologia prostática (15).

Os fatores intrínsecos influenciam as principais populações celulares do órgão por meio de mecanismos parácrinos, autócrinos e intrácrinos. Correspondem, na sua maioria, a diferentes tipos de fatores de crescimento (GF), como o fator de crescimento epidermal (EGF), o de queratinócito (KGF), o de fibroblastos (FGF) e o tipo insulina (IGF) (16) (Figura 2). Assim, a supremacia dos andrógenos na regulação da função e crescimento prostático é devida a sua ação direta, via ligação com ARs ou via mecanismos indiretos decorrentes do estímulo à secreção dos GF. Estes, por sua vez, irão estimular atividades específicas nas células prostáticas, como a proliferação das células epiteliais (KGF) e estromais (FGF). Durante o desenvolvimento embrionário, por exemplo, as células mesenquimais do complexo prostático em desenvolvimento são as primeiras a expressar AR e, então, sob o estímulo androgênico, liberam fatores como o FGF-10 que agem sobre as células epiteliais induzindo a formação dos ductos prostáticos e seu padrão de ramificação característico $(14,15,17,18)$. Por sua vez, a ação direta dos andrógenos se aplica principalmente para a regulação da atividade secretora das células epiteliais (19). Em resumo, as interações entre as populações celulares do estroma e do epitélio são essenciais para o controle do desenvolvimento e histofisiologia prostática. Algumas dessas inter-relações e as principais substâncias envolvidas estão ilustradas na figura 2 .
Com base nessas informações, fica claro que a próstata é um excelente modelo para as investigações das interações epitélio-estroma e dos fatores hormonais que regulam a diferenciação, a morte e a atividade celular. Mais do que isso, inúmeras evidências indicam que o desequilíbrio nessas interações é decisivo na instalação e na progressão das doenças que acometem o órgão (20).

A próstata é um dos órgãos mais sujeitos a alterações durante o envelhecimento, apresentando, frequentemente, um crescimento disfuncional, como é o caso da hiperplasia prostática benigna (HPB), bem como a alta ocorrência de tumores malignos, como o adenocarcinoma prostático (PAC) $(16,21)$. As doenças da próstata levam a um drástico prejuízo da qualidade de vida e os tumores são a segunda causa de mortalidade em alguns países ocidentais. Por esse motivo, a compreensão do controle do funcionamento e a diferenciação das células prostáticas são de grande relevância.

Embora seja encontrada na maioria dos mamíferos, a morfologia da próstata varia significantemente entre as classes. Em roedores, é formada por quatro pares de lobos bilateralmente simétricos designados de anteriores (LA), ventral (LV), lateral (LL) e dorsal (LD) (10). No homem, no cão, no gato e em alguns morcegos, a organização multilobar não é observada nos adultos e a próstata é um órgão compacto que exibe regiões distintas intimamente associadas $(10,22)$.

Os lobos prostáticos de roedores diferem quanto ao padrão de ramificação ductal, à histologia, à sensibilidade hormonal e ao conteúdo secretado $(11,23)$. As regiões da próstata humana também diferem quanto às características histológicas e funcionais e à disposição para as doenças e lesões prostáticas $(10,24)$. Assim, observamse uma maior incidência de HPB na região de transição e um predomínio de PAC na zona periférica (24).

Inúmeros estudos têm tentado estabelecer uma correlação funcional e embriológica entre as regiões da próstata humana e os lobos prostáticos de roedores, contudo, até o momento não existem evidências conclusivas a esse respeito $(13,25)$. Apesar disso, roedores de laboratório, como o rato, o camundongo e mais atualmente o gerbilo da Mongólia, têm sido amplamente utilizados para investigações relativas à histofisiologia $\mathrm{e}$ à patologia da próstata, sendo o LV o mais empregado.

O epitélio secretor da próstata normal é composto por vários tipos celulares inter-relacionados: células-tronco, células basais, células de amplificação transitória ou "transit-amplifying cells" (TAC), células intermediárias, células neuroendócrinas e células luminais secretoras (26). 


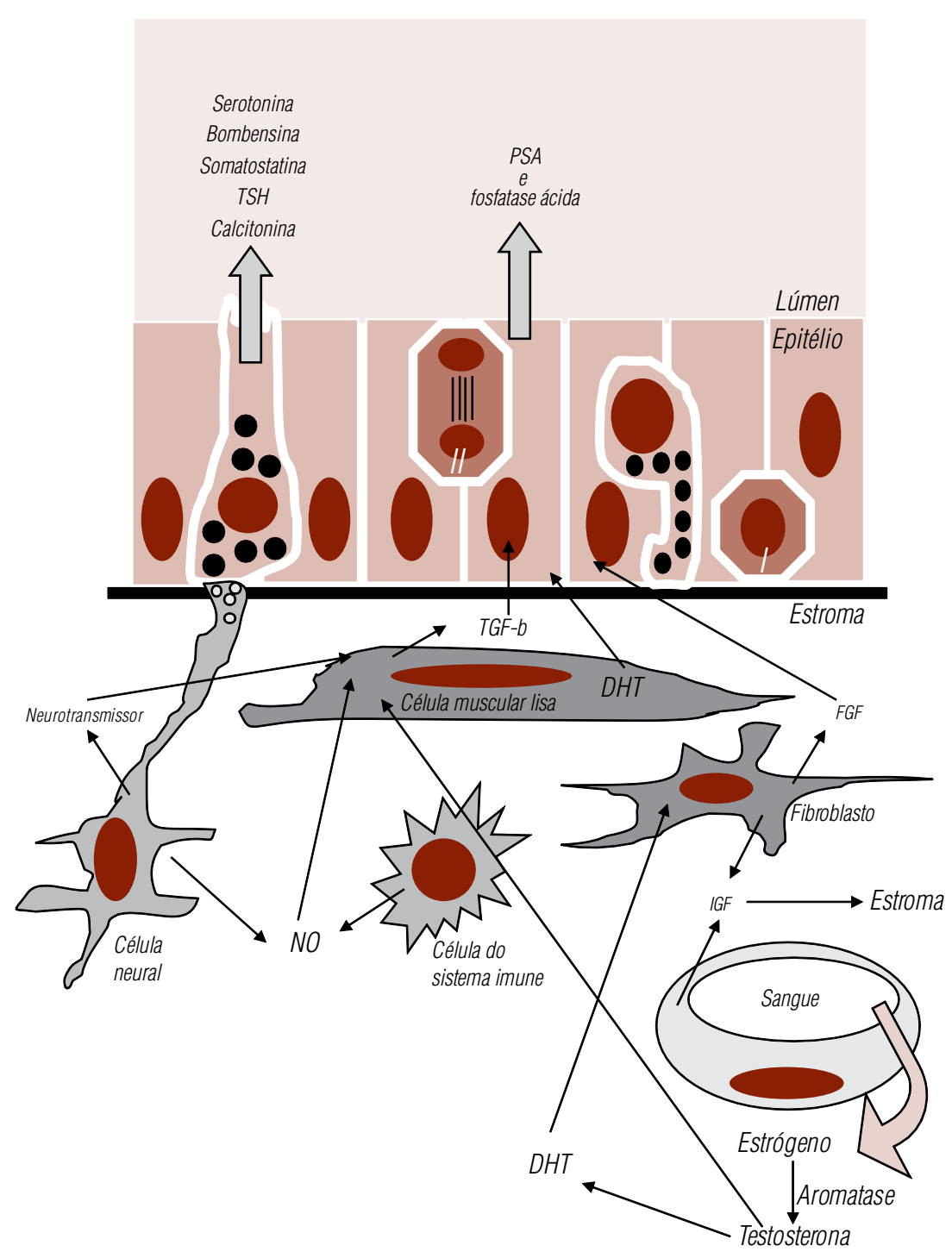

Figura 2. Complexas inter-relações entre o compartimento estromal e epitelial prostático. Modificado de Griffiths e Denis (16). FGF- $\beta$ (fator de crescimento beta), DHT (diidrotestosterona), NO (óxido nítrico), FGF (fator de crescimento fibroblástico), PSA (antígeno prostático específico), I (célula basal), II (célula em divisão).

A diferenciação das células epiteliais prostáticas é um processo hierárquico que requer a divisão das célulastronco e o recrutamento de algumas das células-filhas em direção a células progenitoras intermediárias. No caso da próstata, estas correspondem sequencialmente às células basais, às TAC e às células intermediárias. Assim, à medida que as TACs se proliferam, são translocadas para a região luminal e alteram progressivamente o perfil de expressão gênica em direção às células luminais terminalmente diferenciadas (26). Conforme proposto por vários pesquisadores, esses tipos celulares diferem não apenas quanto à localização e à capacidade de originar outras células, mas também quanto à morfologia, ao padrão de expressão gênica e a respostas a estímulos fisiológicos $(27,28)$. Existem significativas variações no grau de diferenciação celular e nas taxas de morte e proliferação celular ao longo do sistema de ductos da próstata de roedores adultos. As células das regiões centrais são as mais altamente diferenciadas em comparação com as situadas em regiões distais. As taxas de proliferação celular são mais altas nas regiões distais à uretra em comparação com as proximais, enquanto para as taxas de apoptose observa-se o contrário.

\section{DIVERSIDADE ESTRUTURAL E FUNCIONAL DO COMPLEXO PROSTÁTICO DE GERBILO DA MONGÓLIA}

Desde o início dos estudos com o complexo prostático do gerbilo da Mongólia, houve surpresa com o grau 
de diversidade histológica inter e intralobular. Os estudos do presente trabalho focalizavam o LV e os demais componentes do complexo vinham sendo interpretados segundo as descrições de Pinheiro e cols. (7). Nesse sentido, os autores relatavam apenas a existência dos lobos anteriores ou coaguladores, ventrais e dorsais. Contudo, ao se confrontar as observações macroscópicas com as histológicas, parecia existir um maior grau de complexidade do que o apontado até então. Além disso, tal organização anatômica diferia da descrita para a maioria dos roedores, em que o LL também era observado. Visando a melhor entendimento da organização estrutural do complexo prostático do gerbilo e suas possíveis implicações funcionais, bem como a comparações com modelos clássicos de roedores para o estudo da próstata, realizou-se uma ampla descrição desse complexo (8). Para isso, além de se empregar os métodos morfológicos e ultraestruturais de alto padrão, foram implementados métodos de microdissecção, aliados à digestão enzimática. Esses métodos foram o diferencial para o entendimento das relações topográficas entre os lobos e das diferenças regionais quanto à ramificação ductal, à histologia, à ultraestrutura e ao mecanismo de atividade secretora. Eles comprovaram a existência de um componente dorsolateral bem definido. Além disso, foi possível reafirmar, agora com maiores subsídios, que entre todos os lobos prostáticos desse animal o LD é o que apresenta tecido fibromuscular mais desenvolvido, exibindo, assim, um maior grau de semelhança com a próstata humana. Este artigo, embora gerado após a publicação de vários sobre o LV desse animal, estabelece critérios mais acurados e fundamenta estudos futuros sobre o desenvolvimento embriológico pós-natal e de envelhecimento, funcionando como uma referênciachave para as pesquisas a respeito do complexo prostático desse gerbilíneo.

\section{REPERCUSSÕES TECIDUAIS PROSTÁTICAS SOB EFEITOS DE ANTIANDRÓGENOS}

Os andrógenos, juntamente com outros esteroides sexuais, constituem uma classe de hormônios derivados do colesterol. Visto a influência dos andrógenos sobre a homeostasia e o crescimento da próstata, as terapias de supressão androgênica são amplamente utilizadas no tratamento da HPB e do PAC. Os trabalhos de Carvalho e cols. (29) caracterizaram em pormenores o processo de involução prostática perante a supressão androgênica pela castração, chamando a atenção não apenas para atrofia e morte das células epiteliais, mas também para os processos de remodelação dos componentes da matriz extracelular.

A maioria dos estudos com antiandrógenos disponíveis analisava em especial as alterações nos níveis hormonais, de PSA e no tamanho da próstata, existindo uma carência de informações sobre o comportamento dos componentes teciduais, em especial os da matriz extracelular, nessas situações. Portanto, o nível de semelhança entre a resposta prostática à castração química e à cirúrgica não era claro. $\mathrm{Na}$ tentativa de elucidar esse aspecto e fornecer assim maiores subsídios para a compreensão do impacto dos antiandrógenos sobre a próstata, foi realizada a série de estudos, pelo presente grupo de pesquisa, com o objetivo de melhor caracterizar as alterações epiteliais e nos componentes fibrosos do estroma prostático diante de diferentes tratamentos antiandrogênicos (30-34).

A princípio foi avaliado o impacto da flutamida, um antiandrógeno não esteroidal que compete seletivamente com o AR, sobre a próstata lateral de cobaias em diferentes idades (30). Este estudo, baseado em análises citoquímicas, estereológicas e ultraestruturais, indicou uma resposta diferencial ao tratamento com flutamida nas idades púbere, pós-púbere e adulta, sendo a póspúbere menos sensível à terapia. $\mathrm{O}$ aspecto tecidual da remodelação bem como os componentes de matriz extracelular envolvidos são muito similares aos observados na castração cirúrgica (Figura 3). Com o objetivo de obter maiores informações sobre os efeitos da castração cirúrgica e da castração química pela flutamida, esses dois bloqueios foram comparados utilizando o gerbilo como modelo experimental. Entretanto, à semelhança do que ocorre para outros roedores de laboratório $(14,29,35)$, as análises eram direcionadas apenas para o LV. Nas observações feitas pelo presente grupo, era possível constatar que os LD dessa espécie eram mais desenvolvidos que os LVs; além disso, a resposta desse lobo às manipulações hormonais era desconhecida. Assim, surgiu o interesse de comparar as alterações teciduais entre esses lobos diante de duas situações de privação androgênica. Esse estudo (36) levou às seguintes conclusões: 1) à semelhança do descrito por Cordeiro e cols. (30), a flutamida, em doses equivalentes às administradas no tratamento clínico, tem efeitos mais brandos em comparação com a castração; 2) a remodelação estromal apresenta características lobo-específicas, envolvendo, no LV, a ativação de fibroblastos do compartimento subepitelial e o acúmulo de colágeno e uma maior resposta do es- 


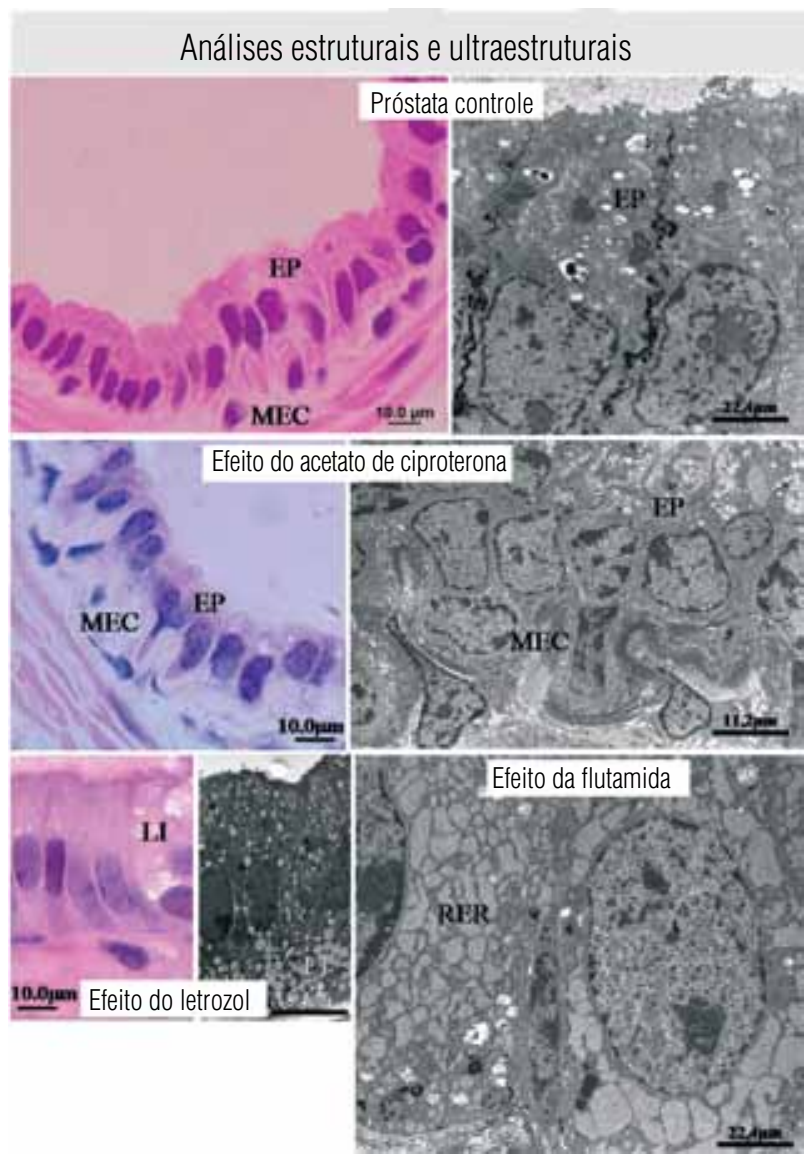

Figura 3. Tecido prostático diante de alguns agentes antiesteroidais. Notar a regressão da altura epitelial (EP), 0 acúmulo de lipídios (LI), o alargamento do retículo endoplasmático rugoso (RER) e o aumento de matriz extracelular (MEC)

troma fibromuscular no LD e 3) nestas situações experimentais, o LV é mais sensível a ambos os tipos de supressão androgênica que o $\mathrm{LD}$, pelo menos no que se refere à atividade secretora do epitélio.

Com vistas a esclarecer se o LD era menos responsivo ao tratamento com antiandrógeno ou exibia uma resposta mais lenta, foram executados experimentos de tratamentos antiandrogênicos de média duração (45 dias). Nesses experimentos também se pretendia comparar entre os lobos do gerbilo os efeitos de antiandrógeno de diferentes naturezas - não esteroidal (flutamida) e esteroidal (acetato de ciproterona). Além dos métodos de análise que vinham sendo utilizados até o momento, nessa época foram implementadas as metodologias para dosagem dos hormônios esteroides. Esses ensaios permitiram uma considerável melhoria na interpretação dos resultados da presente pesquisa, tornando as análises mais abrangentes e os trabalhos, mais competitivos. Aliando dados morfológicos, estereológicos, imunocitoquímicos e hormonais, esse estudo (34) confirmou os achados anteriores de resposta lobo-específica perante os tratamentos antiandrogênicos, evidenciando que a remodelação estromal no LV está relacionada a um aumento de colágeno e condroitina sulfato, o que não ocorre para o LD. Entretanto, este último é também muito responsivo aos tratamentos prolongados com antiandrógenos e, em razão da maior quantidade de estroma fibromuscular, mais adequado para comparações com a próstata humana. Aliado a essas avaliações, em outro momento foram avaliados os níveis de expressão dos receptores de andrógenos na próstata, em diferentes idades, após a castração química pela flutamida, e observou-se que os níveis desses receptores androgênicos respondiam diferentemente nas diferentes idades (37).

Um dos estudos de maior impacto de nossas pesquisas com antiandrógenos foi o que procurava examinar os efeitos da falta de DHT para a histofisiologia prostática. Para isso, foi utilizada uma abordagem experimental de administração da finasterida, um inibidor da enzima 5- $\alpha$-redutase, responsável pela conversão de testosterona em DHT. A finasterida é o principal medicamento utilizado no tratamento da HPB, sendo também indicada para alopecia e acne. Esse estudo demonstrou, com base nas alterações ultraestruturais, que a falta da DHT leva à desdiferenciação das células musculares lisas que passam de um fenótipo contrátil para um secretor, confirmando, assim, o papel ativo dessa população celular na remodelação e na síntese dos componentes da matriz extracelular.

Um dos aspectos que necessitava de esclarecimentos diz respeito aos processos de recuperação que ocorrem na próstata após um período de supressão androgênica, uma questão difícil de ser respondida em estudos clínicos. Para avaliar essa questão, após um mês de castração, os LV da próstata do gerbilo foram analisados em tempos progressivos (1-21 dias) após um mês de castração seguida de reposição de testosterona ou um mês de tratamento antiandrogênico. Os dados obtidos apontaram para uma recuperação morfofuncional mais rápida no segundo tratamento, provavelmente porque as alterações na castração cirúrgica são mais drásticas e em parte irreversíveis (31-33).

\section{ESTUDOS DE EXPOSIÇÃO ESTROGÊNICA NA PRÓSTATA}

Os efeitos dos estrógenos no aparelho reprodutor masculino foram por muito tempo pouco conhecidos e até mesmo subestimados. Apesar disso, o tratamento com estrógenos foi uma das primeiras terapias utilizadas no 
tratamento do câncer de próstata, visto seu efeito negativo sobre o hipotálamo e, consequentemente, sobre a secreção de testosterona. Nas últimas décadas, o papel do estrógeno no organismo masculino foi mais bem compreendido, bem como os potenciais riscos da exposição a agentes estrogênicos (38). Assim, o aumento nos níveis desses esteroides tem sido relacionado com a HPB e mesmo com neoplasias. Os efeitos da exposição ao estrógeno sobre a próstata foram investigados em cobaias em diferentes idades. Os resultados desses experimentos foram agrupados em dois artigos - abaixo mencionados - um focalizando as alterações epiteliais e o outro, as estromais $(39,40)$. Constatou-se que o estrógeno leva a distúrbios proliferativos no epitélio prostático, como a hiperplasia de células basais e as neoplasias intraepiteliais (PIN), bem como a displasias. As características da remodelação estromal na situação de distúrbio estrogênio não apenas confirmou sua ação sobre a proliferação e hipertrofia das células musculares, como também o aumento das fibras elásticas e colágenas. Esses dados vieram reforçar o possível papel desse esteroide na ativação da expressão de genes de elementos de matriz extracelular pelos fibroblastos e células musculares lisas.

Estudos recentes em nosso laboratório têm demonstrado que a associação de antiandrógenos (finasterida) e antiestrógenos (letrozol) leva a alterações importantes no microambiente epitelial e estromal prostático (Figura 3). As alterações histopatológicas observadas vão desde uma simples regressão na atividade secretora, até a indução de importantes prostatites e neoplasias intraepiteliais $(32,33)$.

\section{ENVELHECIMENTO E MODIFICAÇÕES NOS NÍVEIS HORMONAIS: $O$ DESBALANÇO QUE LEVA A DESORDENS PROSTÁTICAS}

Recentemente as investigações foram direcionadas para as modificações que ocorrem durante o envelhecimento $(41,42)$. A comparação das características histológicas e ultraestruturais do LV dos animais jovens, adultos e idosos revelou uma baixa atividade secretora nos primeiros e níveis similares para as outras idades. As principais alterações detectadas com o envelhecimento foram a fibrose estromal com aumento da camada fibromuscular e do colágeno subepitelial, características essas comuns ao tratamento com finasterida. O epitélio também apresentou maior incidência de PINs e alterações degenerativas relacionadas ao acúmulo de lipídeos $(41,42)$.
Considerando que o diabetes é uma doença crônica, que causa graves problemas nos indivíduos senis, e de incidência crescente em países desenvolvidos, que leva a desequilíbrios na secreção de esteroides, e seus efeitos sobre as características teciduais da próstata eram poucos abordados na literatura (43), implementaram-se recentemente no laboratório do presente estudo os efeitos do diabetes sobre a próstata de ratos.

Ao serem analisados os efeitos em longo termo do diabetes experimental não tratado com insulina (44), verificaram-se três tipos de respostas. Para um pequeno grupo de animais, as alterações eram suaves; a maioria exibia uma atrofia prostática bastante distinta da observada com a castração e, para a surpresa de todos, 35\% dos animais apresentavam tumores malignos (45). Esses dados inéditos e de grandes repercussões fornecem novas evidências para interpretação das relações entre o diabetes com os hormônios esteroides e com o câncer de próstata, abrindo nova perspectiva em termos de modelos experimentais para o estudo de ambas as doenças.

$\mathrm{O}$ estudo a respeito da resistência à insulina foi baseado na administração de dexametasona, um glicocorticoide de ação diabetogênica (46). A resistência à insulina em curto termo também leva a atrofia epitelial e aparente diminuição da proliferação dessas células. Contudo, as principais alterações ocorreram no compartimento estromal, com ativação do fenótipo secretor nos fibroblastos e atrofia das células musculares lisas e drásticas lesões nas suas mitocôndrias.

\section{A PRÓSTATA FEMININA: MUDANÇA DE PARADIGMAS}

A ocorrência da próstata associada à região parauretral do aparelho genital feminino ainda surpreende a muitos. Trata-se, provavelmente, do componente desse aparelho menos estudado e conhecido. Em humanos, esse órgão foi designado inicialmente de glândula de Skene (47) e interpretado como uma estrutura resquicial. Entretanto, os trabalhos de Zaviačič e cols. $(48,49)$ demonstram claramente a sua homologia com a próstata masculina, com base nas características morfológicas, na secreção de produtos típicos como o PSA e no acometimento por doenças.

Os estudos sobre esse órgão são pouco abundantes e de natureza exclusivamente descritiva (50). Uma revisão atual e abrangente sobre esse órgão é recomendada (51).

O gerbilo se revelou um modelo interessante para o estudo da próstata feminina devido à sua presença em 
cerca de $90 \%$ das fềmeas em idade reprodutiva. Entretanto, por se tratar de um órgão diminuto e de difícil localização, os trabalhos com essa glândula só se concretizaram neste grupo de pesquisa em consequência da determinação e da habilidade dos pesquisadores envolvidos.

Dentro do universo da próstata feminina, o número de dúvidas é amplo. Nos estudos do presente trabalho, procurou-se responder a algumas das questões mais prementes para a compreensão de sua biologia e significância para a fisiologia feminina. Assim, no primeiro estudo, por meio de análises ultraestruturais, suas principais populações celulares foram descritas, sendo verificada a semelhança desse órgão com o referencial masculino do gerbilo e também com a próstata humana feminina (9). Com base nas características observadas, é reiterado o papel secretor ativo da próstata feminina. Aprofundando a função glandular desse órgão na fềmea, Custódio e cols. (52) analisaram a funcionalidade e a maturação desse órgão em diferentes fases do desenvolvimento pós-natal, em comparação com o LV do macho, a partir da expressão de um marcador de atividade prostática, a fosfatase ácida. Constatou-se, então, que a próstata feminina exibe um padrão de atividade similar nas diferentes fases do desenvolvimento, diferentemente do macho em que a atividade maior é na idade adulta. As implicações dessas diferenças funcionais reforçaram a importância de avaliar o papel da testosterona sobre esse órgão. Assim, os resultados de anos de investigações foram compilados em um único artigo, que provavelmente é o de maior abrangência sobre esse órgão em roedores publicado até o momento (53). Nele foi demonstrado, por meio de análises morfológicas, endocrinológicas e de reconstrução tridimensional, que essa glândula em fêmeas na idade reprodutiva é responsiva à terapia pelo cipionato de testosterona, revelando a curto prazo aumento na atividade proliferativa das células epiteliais e a médio e longo prazo incremento na atividade secretora, inclusive de proteína reativa ao antígeno anti-PSA humano. Foi grande o impacto desse trabalho no meio científico, fato que levou o corpo editorial da revista a escolher uma das figuras para a capa do volume em que o artigo foi publicado. Além disso, a divulgação desses resultados na imprensa jornalística e televisiva causou, da mesma maneira, grande impacto.

$\mathrm{Na}$ busca de maior compreensão da regulação hormonal da próstata feminina, implementou-se um estudo dessa glândula ao longo do ciclo estral (54) e os resultados demonstraram que a atividade secretora da próstata feminina tem uma profunda relação com a fase de estro do referido ciclo, além de ter uma fase de repouso na fase de diestro I. Foram ainda avaliadas as possíveis relações das alterações teciduais aos níveis séricos de testosterona e estrógeno nas diferentes idades (55) e, interessantemente, verificou-se que, assim como em machos, as alterações histopatológicas no envelhecimento são influenciadas pelo desequilíbrio na razão testosterona/estrógeno (56). Esses dados trazem nova luz para o delineamento de experimentos futuros e solidificam as contribuições em termos da próstata feminina.

\section{CONSIDERAÇÕES FINAIS E PERSPECTIVAS}

Os resultados aqui compilados refletem os esforços conjuntos de pesquisadores comprometidos com a melhoria das condições de pesquisa do Grupo de Estudos em Biologia da Reprodução da Unesp de São José do Rio Preto e intensamente motivados na geração de conhecimento e formação de recursos humanos para a pesquisa científica na área de biologia da próstata dos roedores.

$\mathrm{Na}$ área de reprodução, a consulta de bancos públicos de dados científicos na rede internacional revela que o grupo do presente trabalho desponta na quantidade de artigos sobre gerbilo Meriones unguiculatus. Assim, o conjunto dos dados publicados mostra que o complexo prostático desse modelo experimental difere dos outros roedores de laboratório, sugerindo uma maior analogia com a próstata humana. A possível aplicação desse modelo animal em estudos experimentais que permitam uma maior compreensão das doenças da próstata humana é, sem dúvida, uma das principais contribuições.

Aplicando as descrições anatômicas do complexo prostático na interpretação das relações filogenéticas nos Rodentia, o gerbilo apresenta diferenças importantes, tais como o maior desenvolvimento do lobo dorsolateral, diferenças essas que merecem ser mais bem investigadas no que se refere às implicações para evolução, bem como para os mecanismos reprodutivos dessa espécie. É possível que a lobulação prostática possa ser um caráter importante para a filogenia do grupo.

Na linha de Biologia Prostática, estão sendo realizadas investigações sobre o comportamento dos componentes não fibrilares da matriz extracelular do estroma em situações de supressão androgênica, distúrbios metabólicos com o diabetes e com a obesidade na transformação celular. Outro ponto a ser avaliado é o papel dos fibroblastos nessas situações, uma vez que os estudos 
têm atribuído à célula muscular lisa um papel ativo na remodelação e os fibroblastos têm sido pouco analisados. As características da diferenciação celular, tanto epitelial quanto estromal, diante das situações acima descritas, também estão sendo determinadas com o uso de marcadores específicos.

Agradecimentos: os autores agradecem as agências financiadoras nacionais: a Fundação de Amparo à Pesquisa do Estado de São Paulo (Fapesp), o Conselho Nacional de Desenvolvimento Científico e Tecnológico (CNPq) e a Coordenação de Aperfeiçoamento de Pessoal de Nível Superior (Capes) pelo fomento à pesquisa e pelas bolsas concedidas aos alunos e aos pesquisadores. Ao apoio técnico dos biólogos Luis Roberto Falleiros Júnior e Rosana Silistino de Souza.

Declaração: os autores declaram não haver conflitos de interesse científico neste estudo.

\section{REFERÊNCIAS}

1. Schwentker V. The gerbil - A new laboratory animal. Veterinarian. 1963;6:5-9.

2. Nawaa $Y$, Okada M, Arizono N. Histochemical and cytochemical characterizations of mucosal and connective tissue mast cells of Mongolian gerbils. Int Arch Allergy Imunol. 1994;104:249-54.

3. Muller M, Nielsen JT. Effect of superior cervical ganglionectomy on monoamine content in the epithalamic area of the Mongolian Gerbil - A fluorescence histochemical study. Cell Tissue Res. 1979;201(1):1-9.

4. Ninomiya $H$, Nakamura T. Postnatal development of the testis in the Mongolian gerbil, Meriones unguiculatus. Jikken Dobutsu. 1987;36(1):65-72.

5. Segatelli TM, Almeida CCD, Pinheiro PFF, Martinez M, Padovani $\mathrm{CR}$, Martinez FE. Kinetics of spermatogenesis in the Mongolian gerbil (Meriones unguiculatus). Tissue Cell. 2002;34(1):7-13.

6. Peruquetti $R$, Taboga S, de Azeredo-Oliveira M. Characterization of Mongolian Gerbil Chromatoid Bodies and Their Correlation with Nucleolar Cycle During Spermatogenesis. Reprod Domest Anim. 2009 (no prelo).

7. Pinheiro PFF, Almeida CCD, Segatelli TM, Martinez M, Padovani $\mathrm{CB}$, Martinez FE. Structure of the pelvic and penile urethra - Relationship with the ducts of the sex accessory glands of the Mongolian gerbil (Meriones unguiculatus). J Anat. 2003;202:431-44.

8. Rochel SS, Bruni-Cardoso A, Taboga SR, Vilamaior PS, Góes RM. Lobe identity in the Mongolian gerbil prostatic complex: a new rodent model for prostate study. Anat Rec (Hoboken). 2007;290(10):1233-47.

9. dos Santos FC, Carvalho HF, Góes RM, Taboga SR. Structure, histochemistry, and ultrastructure of the epithelium and stroma in the gerbil (Meriones unguiculatus) female prostate. Tissue Cell. 2003;35(6):447-57.

10. Price D. Comparative aspects of development and structure in the prostate. Nat Can Inst Monogr. 1963;12:1-27.

11. Aumüller G, Seitz J. Protein secretion and secretory process in male accessory sex gland. Int Rev Cytol. 1990;121:127-231.

12. Lee C, Kozlowski JM, Grayhack JT. Intrinsic and extrinsic factors controlling benign prostatic growth. Prostate. 1997;31:131-8.

13. Marker PC, Donjacour AA, Dahiya R, Cunha GR. Hormonal cellular and molecular control of prostatic development. Develop Biol. $2003 ; 253: 165-74$.
14. Vilamaior PS, Taboga SR, Carvalho HF. Postnatal growth of the ventral prostate in Wistar rats: a stereological and morphometrical study. Anat Rec A Discov Mol Cell Evol Biol. 2006;288(8):885-92.

15. Cunha G, Donjacour AA, Cooke PS, Mee S, Bigsby RM, Higgins $\mathrm{SJ}$, et al. The endocrinology and developmental biology of the prostate. Endocr Rev. 1987;8:338-62.

16. Griffiths K, Denis LJ. Further insights into endocrine disease: regulation of prostatic growth. In: The 4th International Consultation on Benign Prostatic Hyperplasia. Paris; 1997. p. 1-40.

17. Kurita $T$, Wang $Y Z$, Donjacour AA, Zhao C, Lydon JP, O'Malley $\mathrm{BW}$, et al. Paracrine regulation of apoptosis by steroid hormones in the male and female reproductive system. Cell Death Differ. 2001;8:192-200.

18. Bruni-Cardoso A, Vilamaior PS, Taboga SR, Carvalho HF. Localized matrix metalloproteinase (MMP)-2 and MMP-9 activity in the rat ventral prostate during the first week of postnatal development. Histochem Cell Biol. 2008;129(6):805-15.

19. Cunha GR, Young P. Inability of Tfm (testicular feminization) epithelial cells to express androgen-dependent seminal vesicle secretory proteins in chimerical tissue recombinants. Endocrinology. 1991;128:3293-8.

20. Tuxhorn JA, Ayala GE, Smith MJ, Dang TD, Rowley DR. Reactive stroma in human prostate cancer: induction of myofibroblast phenotype and extracelular matrix remodeling. Clin Cancer Res. 2002;8:2912-23.

21. Taboga SR, Vidal BC. Collagen fibers in human prostatic lesions: histochemistry and anisotropies. J Submicrosc Cytol Pathol. 2004;35(1):11-6.

22. McNeal JE. Relationship of the origin of benign prostatic hypertrophy to prostatic structure of man and other mammals. In: Hinman $\mathrm{F}$ (ed.). Benign Prostatic Hypertrophy. New York: SpringerVerlag; 1983. p. 152-66.

23. Banerjee PP, Banerjee S, Lai JM, Strandberg JD, Zirkin BR. Agedependent and lobe-specific spontaneous hyperplasia in Brown Norway rat prostate. Biol Reprod. 1998;59:1163-70.

24. De Marzo AM, Platz EA, Sutcliffe S, Xu J, Gronberg H, Drake CG, et al. Inflammation in prostate carcinogenesis. Nature. 2007;7:256-69.

25. Shappell SB, Thomas GV, Roberts RL, Herbert R, Ittmann MM, Rubin MA. Prostate pathology of genetically engineered mice: definitions and classification. The consensus report from the Bar Harbor meeting of the Mouse Models of Human Cancer Consortium Prostate Pathology Commitee. Cancer Research. 2004;61:2270-305.

26. Isaacs JT, Coffey DS. Etiology and disease process of benign prostatic hyperplasia. Prostate. 1989;2(Suppl):33-50.

27. De Marzo AM, Nelson WG, Meeker AK, Coffey DS. Stem cell features of benign and malignant prostate epithelial cells. J Urol. 1998;160:2381-92.

28. Kurita T, Medina RT, Mills AA, Cunha GR. Role of p63 and basal cells in prostate. Development. 2004;131(20):4955-64.

29. Vilamaior PSL, Felisbino SL, Taboga SR, Carvalho HF. Collagen fiber reorganization in the rat ventral prostate following androgen deprivation: a possible role for smooth muscle cells. Prostate. 2000;45(3):235-8.

30. Cordeiro RS, Scarano WR, Góes RM, Taboga SR. Tissue alterations in the Guinea pig lateral prostate following antiandrogen flutamide therapy. Biocell. 2004;28(1):21-30.

31. Corradi LS, Góes RM, Carvalho HF, Taboga SR. Inhibition of 5-alpha-reductase activity induces stromal remodeling and smooth muscle de-differentiation in adult gerbil ventral prostate. Differentiation. 2004;72(5):198-208.

32. Corradi LS, Campos SG, Santos FC, Vilamaior PS, Góes RM, Taboga SR. Long-term inhibition of 5-alpha reductase and aromatase changes the cellular and extracellular compartments in gerbil ventral prostate at different postnatal ages. Int J Exp Pathol. 2009;90(1):79-94. 
33. Corradi LS, Góes RM, Vilamaior PS, Taboga SR. Increased androgen receptor and remodeling in the prostatic stroma after the inhibition of 5 -alpha reductase and aromatase in gerbil ventral prostate. Microsc ResTech. 2009 (no prelo).

34. Oliveira SM, Leite Vilamaior PS, Corradi LS, Góes RM,Taboga SR. Cellular and extracellular behavior in the gerbil (Meriones unguiculatus) ventral prostate following different types of castration and the consequences of testosterone replacement. Cell Biol Int. 2007;31(3):235-45.

35. Vilamaior PSL, Taboga SR, Carvalho HF. Modulation of smooth muscle cell function: morphological evidence for a contractile to synthetic transition in the rat ventral prostate after castration. Cell Biol Intern. 2005;29:809-16.

36. Góes RM, Zanetoni C, Tomiosso TC, Ribeiro DL, Taboga SR. Surgical and chemical castration induce differential histological response in prostate lobes of Mongolian gerbil. Micron. 2007;38(3):231-6.

37. Cordeiro RS, Scarano WR, Campos SG, Santos FC, Vilamaior PS, Góes RM, et al. Androgen receptor in the Mongolian gerbil ventral prostate: evaluation during different phases of postnatal development and following androgen blockage. Micron. 2008;39(8):1312-24.

38. Risbridger GP, Ellem SJ, Mcpherson SJ. Estrogen action on the prostate gland: a critical mix of endocrine and paracrine signaling. J Mol Endocrinol. 2007;39(3):183-8.

39. Scarano WR, Cordeiro RS, Góes RM, Carvalho HF, Taboga SR. Tissue remodeling in Guinea pig lateral prostate at different ages after estradiol treatment. Cell Biol Int. 2005;29(9):778-84.

40. Scarano WR, de Sousa DE, Campos SG, Corradi LS, Vilamaior PS, Taboga SR. Oestrogen supplementation following castration promotes stromal remodelling and histopathological alterations in the Mongolian gerbil ventral prostate. Int J Exp Pathol. 2008;89(1):25-37.

41. Pegorin de Campos SG, Zanetoni C, Góes RM, Taboga SR. Biological behavior of the gerbil ventral prostate in three phases of postnatal development. Anat Rec A Discov Mol Cell Evol Biol. 2006;288(7):723-33.

42. Campos SG, Zanetoni C, Scarano WR, Vilamaior PS, Taboga SR. Age-related histopathological lesions in the Mongolian gerbil ventral prostate as a good model for studies of spontaneous hormone-related disorders. Int J Exp Pathol. 2008;89(1):13-24.

43. Ribeiro DL, Caldeira EJ, Candido EM, Manzato AJ, Taboga, SR, Cagnon VA. Prostatic stromal microenvironment and experimental diabetes. Eur J Histochem. 2006;50(1):51-60.
44. Ribeiro DL, Marques SF, Alberti S, Spadella CT, Manzato AJ, Taboga $S R$, et al. Malignant lesions in the ventral prostate of alloxaninduced diabetic rats. Int J Clin Exp Pathol. 2008;89(4):276-83.

45. Ribeiro DL, Taboga SR, Góes RM. Diabetes induces stromal remodelling and increase in chondroitin sulphate proteoglycans of the rat ventral prostate. Int J Exp Pathol. 2009;90(4):400-11.

46. Ribeiro DL, Rafacho A, Bosqueiro JR, Taboga SR, Góes RM. Cellular changes in the prostatic stroma of glucocorticoid-treated rats. Cell Tissue Res. 2008;332(3):499-508.

47. Skene AJC. The anatomy and pathology of two important glands of the female urethra. Am J Obstet Dis Women Child 1880;13:265-70.

48. Zaviačič M. The Female Prostate: from vestigial Skene's paraurethral glands and ducts to woman's functional prostate. Bratislava, Slovakia: Slovack Academic Press; 1999. p. 171.

49. Zaviačič $M$, Ablin RJ. The female prostate and prostate-specific antigen. Imunohistochemical localization, implications of this prostate marker in women and reasons for using the term "prostate" in human female. Histol Histopathol. 2000;15(1):131-42.

50. Flamini MA, Barbeito CG, Gimeno EJ, Portiansky EL. Morphological characterization of the female prostate (Skene's gland or paraurethral gland) of Lagostomus maximus maximus. Annals Anatomy. 2002;184:341-5.

51. Santos FC, Taboga SR. Female prostate a review about biological reprecursions of this gand in humans and rodents. Anim Reprod. 2006;3:3-18.

52. Custódio AM, Góes RM, Taboga SR. Acid phosphatase activity in gerbil prostate: comparative study in male and female during postnatal development. Cell Biol Int. 2004;28(5):335-44.

53. Santos FC, Leite RP, Custódio AM, Carvalho KP, Monteiro-Leal LH, Santos $A B$, et al. Testosterone stimulates growth and secretory activity of the female prostate in the adult gerbil (Meriones unguiculatus). Biol Reprod. 2006;75(3):370-9.

54. Fochi RA, Perez AP, Bianchi CV, Rochel SS, Góes RM, Vilamaior PS, et al. Hormonal oscillations during the estrous cycle influence the morphophysiology of the gerbil (Meriones unguiculatus) female prostate (skene paraurethral glands). Biol Reprod. 2009;79(6):1084-91.

55. Custodio AM, Santos FC, Campos SG, Vilamaior PS, Góes RM, Taboga SR. Aging effects on the mongolian gerbil female prostate (Skene's paraurethral glands): structural, ultrastructural, quantitative, and hormonal evaluations. Anat Rec (Hoboken). 2008;291(4):463-74.

56. Custodio AMG, Santos FCA, Campos SGP, Vilamaior PSL, Oliveira $\mathrm{SM}$, Góes RM, et al. Disorders related with ageing in the gerbil female prostate (Skene's paraurethral glands). Int J Exp Path. 2009 (no prelo). 